\title{
Acemoglu Meets Lucas: Institutions, Human Capital and Economic Growth
}

\author{
Suzana Quinet de Andrade Bastos ${ }^{1}$, Fabio Gama ${ }^{1} \&$ Tiana de Paula Assis ${ }^{1}$ \\ ${ }^{1}$ Federal University of Juiz de Fora, Juiz de Fora, MG 36036-900, Brazil \\ Correspondence: Fabio Gama, PhD student at PPGE / UFJF, Federal University of Juiz de Fora, Juiz de Fora, MG \\ 36036-900, Brazil.
}

Received: May 30, 2020

Accepted: July 8, 2020

Online Published: July 21, 2020

doi:10.5430/ijba.v11n4p98

URL: https://doi.org/10.5430/ijba.v11n4p98

Funding: This work was supported by Fundação de Amparo à Pesquisa do Estado de Minas Gerais (APQ-02434-15 $-50520)$

\begin{abstract}
This paper proposes a reinterpretation of Lucas endogenous growth model (1988), once we add an institutional component as one of its determinants. Firstly, the paper develops a theoretical model that links human capital and institutions. Our modelling strategy establishes the human capital accumulation function as being derived from an endogenous process in which the institutional performance is a booster for the economy's growth. The essay uses a 40-country panel data of the years 2000, 2005 and 2010 and implements a Pooled Ordinary Least Squares (POLS) analysis - alongside instrumental variables (IV) - aiming to validate empirically the model proposed. We verify that Lucas' model overestimates the human capital contribution as we evaluate the significant impact that economic and political institutions have on the capability of human capital foment growth. Additionally, our estimations also suggest that human capital is, effectively, institutionally driven and works as a channel for the institutions.
\end{abstract}

Keywords: political institutions, economic institutions, human capital, endogenous growth

JEL: O43, O11, C33, C36

\section{Introduction}

The causes involved in promoting long term economic growth have always been a fundamental subject of economic studies. Historically, since the eighteenth and nineteenth centuries, great economists as Adam Smith (1776) and David Ricardo (1817) were already bringing contributions to the understanding of what economic growth would be and what some of the mechanisms for reaching it would be. From the 20th century, the discussion is replaced by large contributions based on theoretical modelling. The Harrod-Domar model, developed independently by the economists Roy F. Harrod (1939) and Evsey Domar (1946), demonstrates how the rate of economic growth is directly related to the savings and labour force levels in the economy. The model proposes that is expected that the long-term balance could not be achieved once it wouldn't be possible to guarantee an investment level in order to achieve continuous expansion of the economic activity. Since the agents operate under expectations (Harrod 1939; Barcelos and Salles 2011) capital is, effectively, institutionally driven and works as a channel for the institutions.

In 1956, the American economist Robert M. Solow criticized and proposed improvements to the theoretical construction of Harrod and Domar, launching what became known as the exogenous growth model - the neoclassical model. Solow introduced the contribution of technology to economic growth and assumed that this factor, as well as the labour force factor, grows at constant rates, both given exogenously. In opposition to the Harrod-Domar model, Solow abandoned the capital and labour condition that cannot be allocated to each other in production, which allowed the adjustment between these two factors in a state of continuous and balanced long-term growth. Solow's (1956) model also implied that all countries-with identical preferences and technological level-have their growth rates and income level in a movement of convergence. This way, poorer economies grow at a faster rate due to its lower labour-capital ratio and therefore its higher marginal product.

Committed to clarify the disparities between the empirical facts observed in some economies and what Solow model predicted, Paul Romer (1986) and Robert Lucas (1988) inaugurates the studies on the economic growth determinants 
based on an endogenous understanding of its variables and the addition of the human capital factor to the analysis. In the new model, human capital - expressed by education, health, and experience - can generate positive externalities and increasing returns in productivity. With such properties, the human capital factor reproduces an increase of physical capital and labour productivity, continuously allowing countries to foster economic growth. Unlike Solow, Romer asserts that richer economies can grow faster than the less advanced ones. The author could then justify the empirical findings in which high average GDP growth rates were noted in richer countries such as the USA and Western Europe while very modest growth was achieved in the poorer countries such as those located in Central America.

The theoretical construction developed by the school of endogenous growth deserves great merit. However, the authors failed to model institutions, only allowing us to make assumptions regarding how these may influence growth (Note 1). The theory also left unclarified what is considered one of the main driving forces for achieving continuous economic growth: the process of human capital accumulation. Nevertheless, accumulating knowledge greatly depends on how institutions perform. According to Tebaldi and Elmslie (2008 p. 36), good institutions can contribute to the process of registering new patents, disseminate ideas and promote cooperation across researchers, speed up diffusion of scientific knowledge, improve enforcement of property rights and to reduce the uncertainty of new projects; all factors that stimulate $\mathrm{R} \& \mathrm{D}$ activities.

Faced with this challenge, one of the main contemporaneous authors who attempt to fill this gap is Acemoglu. In his work, the author highlights the role that the institutions of a country have as promoters of economic growth, highlighting their ability to create and ensure the environment conducive to economic growth (Acemoglu et al. 2005). In particular, as opposed to Glaeser et al. (2004), Acemoglu asserts that the quality of human capital does not create good institutions, but efficient institutions enable human capital to flourish instead. Therefore, economic growth consists of approximate determinants (e.g. factors of production, innovation, and physical and human capital accumulation) and fundamental determinants (Note 2). These fundamental determinants, truly responsible for the origin of prosperity, are the countries' institutions. Institutions would then lead to higher levels of productivity, human capital, and physical capital, which reproduce economic growth as we know it - rising GDP per capita (Acemoglu et al. 2014).

Therefore, institutions, as well as how they operate, become a primary subject once we aim for precise comprehension of economic growth. Inspired by the institutionalist theory, our goal in this paper is to show that, unlike Lucas (1988), internalizing the quality of the institutions as the main determinant for changes in the stock of human capital is a fundamental procedure for obtaining accurate results. For such, we develop a new theoretical model in which the institutions are internalized as boosters for human capital accumulation. Next, we constructed a human capital index and implemented a Pooled Ordinary Least Squares (POLS) analysis - alongside instrumental variables (IV) - for 40 countries in the years of 2000, 2005 and 2010. Such effort allows us then to empirically test how the variables of Lucas' model behave - as well as the level of growth - when the human capital variable is under influence of institutional performance.

As predicted by institutionalist authors as Acemoglu, our results demonstrate that the level of economic and political institutions of a country plays a key role in the economic growth through human capital. Our evidence indicates that Lucas (1988) model overestimates the contribution of human capital to growth. Once in the presence of institutions, there is a reduction in the human capital-GDP per capita elasticity. Other evidence found by our paper reinforces the correlation between the institutional variable and human capital when is noted that in the Extended Model the effect of physical capital remains statistically unchanged if compared to the same effect estimated through Lucas' model. Therefore, is possible to conclude, like Acemoglu et al (2014), that institutions can establish an influence channel through human capital in the growth process of the countries.

The structure of the paper is as follows. Section 2 discusses the theory regarding institutions. Section 3 presents the theoretical model. Section 4 addresses the empirical model and the database. In section 5 , the model empirical results are displayed. Finally, section 6 concludes the paper.

\section{How Institutions Are Molded}

The institutionalist theory has as its starting point the contributions of Douglass North (1993). For the author, the true economic growth would occur with the increase in the level of per capita population income, and this level would remain constant - or in a steady state - during the periods in which individuals did not obtain sufficient incentives to develop economic activities. The author indicates an effective economic organization as a crucial factor for economic growth. According to North and Thomas (1973 p. 2): 'The factors we mentioned (innovation, economies of scale, education, capital accumulation, etc.) are not the causes of growth; they are growth'. Therefore, the author 
characterizes institutions as a channel through which human - and physical - capital makes use to result in economic growth, serving as a means and end in this process.

Following North and Thomas (1973), Acemoglu et al (2014) establish that the determinants of economic growth are composed of approximate and fundamental determinants. The approximate determinants (e.g. factors of production, innovation, accumulation of physical and human capital) unlike what is commonly assumed would not be responsible for the level of prosperity of nations, but prosperity itself. According to the authors, the fundamental determinants would be the truly responsible for the origin of prosperity and would answer questions such as: 'Why do certain countries invest more in their education system?' or 'Why do people save and invest in physical capital?'. Recognizing institutions as the fundamental determinants, the authors argue that growth with rising levels of productivity, human capital and physical capital would be the result of how these institutions evolved over time.

Acemoglu et al (2005), defend the important role of economic institutions in creating incentives for large agents of society, such as investments in human and physical capital, as well as technology. According to the authors, the disparities observed in the levels of economic growth between nations are the result of the interaction between critical circumstances - such as major historical events - and the institutional characteristics of each country. These critical circumstances (Note 3) can be viewed as random events - or shocks - that hit societies and demand an institutional response. In such cases, pre-existing institutions (Note 4), when faced with these events, will move towards a differentiation that, over time, will lead to superior or inferior economic performance compared to other nations (Acemoglu; Robinson 2012, p. 113).

In an effort to shed light on what would make institutions good - with the means to promote economic success -, Acemoglu et al (2005) bring the term 'inclusive institutions'. Unlike 'extractive institutions', these have a politically centralized framework and allow society to have access to the resources available, serving the purpose of the majority and not the interests of a small elite of some narrow group (Note 5). However, once political centralization is not followed by economic pluralism, institutions can still be seen as politically extractive. These institutions may even generate some degree of prosperity - significant even. Nevertheless, this growth dynamic cannot endure for long periods (Note 6). As a result, an innovative-deprived scenario is established, leading to the collapse of this system. According to Acemoglu and Robinson (2012 p. 136): '[...] in all cases of growth under extractive institutions, the process excluded the possibility of technological change and was therefore not sustained. At first, the pace of growth slowed until it completely collapsed.'

Therefore, it is the political institutions of the countries - extractive or not - that usually dictate which model of economic institutions will prevail (Acemoglu and Robinson 2012). For Acemoglu, this dynamic established between political and economic institutions can be understood by using the 'vision of social conflict' developed by North (1981). According to this, the decision of which institutions - political and economic - will prevail in a country is not concentrated, at all times, in the hands of most citizens, but in the hands of elite. Once in possession of this power, this group makes use of these same institutions to achieve a higher level of self-welfare, even though this implies underdevelopment for the rest of the population (Acemoglu et al. 2005). Therefore, amid the temporal game of interests in which different parts of society act for their own benefit, the institutional apparatus will eventually be built and directed in favour of those individuals who already hold some power within this system.

Acemoglu et al (2012) deal with the distribution of this political power in society highlighting two types of powers established in social relations: de jure and de facto political power - which have different origins. The first refers to the power derived from institutions - established by them. Acemoglu et al. (2005, p. 7) highlight: 'For example, in the monarchy, political institutions allocate all de jure power to the monarch and place few restrictions on their exercise'. The second refers to the political power attributed to determined individuals, even if not foreseen by the institutions - unconstitutionally. The de facto political power would be underpinned by the economic resources that certain portions of society possess. In this way, these groups would be capable of strongly influence the course of the institutions in a country by relying on their wealth so that mechanisms - e.g. protests, weapons, army co-optation, among others - could promote changes at an institutional level in favour of their agendas.

The de facto power proves to be responsible for pointing the direction in which political institutions will follow. As a result, it also determines the de jure power configuration within social relations. This way, resource allocation is imperative for understanding the determinants of economic growth. Acemoglu also highlights the endogeneity presented by political and economic institutions where: '[...], political institutions are also endogenous; the current balance of political power, incorporating both de jure and de facto elements, also determines future political institutions' (Acemoglu et al. 2005 p. 451). Therefore, de jure and de facto political power in a period t will influence the choice of the economic institutions in this same period and the political institutions in the next period 
$(\mathbf{t}+\mathbf{1})$. The economic institutions arising from this selection, in turn, will be decisive in determining the economic growth of period $\mathbf{t}$ and the resource distribution for period $\mathbf{t}+\mathbf{1}$.

It is also essential to understand that inclusive economic institutions cannot support politically extractive institutions. If they did, those economic institutions will either become extractive or lead to a dynamic transformation of formerly extractive political institutions into inclusive ones (Acemoglu and Robinson 2012). Therefore, creative destruction is prevented by the ones in charge of extractive intuitions once this process clearly would result in a shifting of economic and, ultimately, political influence as well. The authors describe the 'controlled stagnation' allowed by determined agents as being intended to ensure that there will be fruits to be harvest since the best ones are reserved for those in power. Acemoglu et al. (2005 p. 397) also highlight:

'Some forms of societal organization encourage people to innovate, take risks, save for the future, find better ways of doing things, learn and educate themselves, solve collective action problems and provide public goods. Others don't.'

\section{The Theoretical Model}

Assuming a Cobb Douglas production function, Lucas' model (1988) states that the level of economic activity is a function of physical capital, human capital, and a set of factors that are constant over time. In formal terms, equation (1) summarizes the central concept of the model:

$$
Y_{t}=A k_{t}^{\beta}\left(u_{t} h_{t}\right)^{1-\beta}
$$

Where $\mathrm{Y}$ is the level of economic activity of a particular country in period $\mathbf{t}, \mathbf{A}$ is a constant, $\mathbf{k}$ and $\mathbf{h}$ are, respectively, the physical capital and human capital accumulated over a given period, and $\mathbf{u}$ is the portion of human capital intended of use in the production of goods and services. Despite Lucas advances over predecessor models, he did not discuss the role that institutions play for the level of economic activity. According to the author, institutional differences in the level of activity would be captured within the constant parameter of his model - therefore, their effect on the product over time would not be modelled.

Based on Acemoglu et al. (2014), this paper proposes a new version of Lucas' model, 2, in which we add institutions as accelerators for the human capital as well as a fundamental determinant for growth. Our hypothesis relies on the idea that the institutional level of countries enhances the effect of human capital on the level of production (Note 7). Equation 2 expresses how this relation is established (Note 8):

$$
y=A k_{t}^{\beta}\left(u_{t} h_{t} I_{t}\right)^{1-\beta} 0<\beta<1 \& 0<u_{t}<1
$$

Following Lucas (1988), as a way to solve the model, we resort to the problem of maximization of utility by agents subject to intertemporal constraints. The representative agent maximizes the present value of the utility flow of consumption, $u(c)$, over its lifetime, discounted by their intertemporal preference rate $\rho$. The utility function of the agent can be given by:

$$
U(C t)=\int_{0}^{\infty} e^{-\rho t} \frac{c_{t}^{1-\sigma}}{1-\sigma}
$$

Where $\sigma$ is a risk aversion coefficient, assuming $\sigma>0$.

Also, in each period, the agent seeks to maximize their intertemporal utility, subject to the following restrictions:

$$
\dot{k}=A k_{t}^{\beta}\left(u_{t} h_{t} I_{t}\right)^{1-\beta}-C
$$

Equation 4 states that the change in capital stock is the production of the period minus consumption - i.e. investment equals savings:

$$
\dot{h}=\theta h\left(1-u_{t}\right)
$$

With $\theta>0$.

In the accumulation of knowledge, (5) agents learn when they study! Thus, we relate the accumulation of human capital with the time spent outside work $(1-u)$.

$$
I_{t}=J e^{n t+\sum_{\tau=1}^{t} \varepsilon_{\tau}}
$$

Finally, institutions of period $\mathrm{t}$ are an exponential function of a constant $\mathrm{n}$ and shocks $(\varepsilon)$ which accumulate over time (6a). Nevertheless, Acemoglu et al (2005) state that shocks happen randomly during the process of institutional 
evolution - i.e. they can be positive or negative and do not follow a predetermined pattern. Therefore, we assume that - at the limit - the sum of shocks is zero. Rewriting $6 \mathrm{a}$ has $6 \mathrm{~b}$.

$$
I_{t}=J e^{n t}
$$

Thus, the Hamiltonian of current value, $\mathrm{L}$, is given by:

$$
L=\int_{1}^{\infty} e^{-\rho t} \frac{c_{t}^{1-\sigma}}{1-\sigma}+V\left\{A k_{t}^{\beta}\left(u_{t} h_{t} J e^{n t}\right)^{1-\beta}-C\right\}+\lambda\left\{\theta h\left(1-u_{t}\right)\right\}
$$

The first order conditions are as follows:

$$
\begin{gathered}
\frac{\partial L}{\partial u}=V\left\{A k_{t}^{\beta}(1-\beta)\left(h_{t} J e^{n t}\right)^{1-\beta} u_{t}^{-\beta}\right\}-\lambda \theta h=0 \\
\frac{\partial L}{\partial c}=e^{-\rho t} c_{t}^{-\sigma}-V=0 \\
\frac{\partial L}{\partial k}=V\left\{\beta A k_{t}^{\beta-1}\left(u_{t} h_{t} J e^{n t}\right)^{1-\beta}\right\} \\
\frac{\partial L}{\partial h}=V\left\{(1-\beta) A k_{t}^{\beta}\left(u_{t} J e^{n t}\right)^{1-\beta} h_{t}^{-\beta}\right\}+\lambda\left\{\theta\left(1-u_{t}\right)\right\}
\end{gathered}
$$

Transversality conditions

$$
\begin{gathered}
\frac{\partial L}{\partial k}=-\dot{V} \\
\frac{\partial L}{\partial h}=-\dot{\lambda} \\
\frac{\partial L}{\partial u}=0
\end{gathered}
$$

Resolving it, we have the growth rates of consumption, capital stock, human capital and output, respectively.

$$
\begin{gathered}
\frac{\dot{c}}{c}=\gamma=\frac{\theta-\rho}{\sigma}+\frac{n}{\sigma} \\
\frac{\dot{k}}{k}=\gamma=\frac{\theta-\rho}{\sigma}+\frac{n}{\sigma} \\
\gamma_{h}=\frac{(\theta-\rho)}{\sigma}+n\left(\frac{1}{\sigma}-1\right) \\
\frac{\dot{y}}{y}=\beta\left[\frac{\theta-\rho}{\sigma}+\frac{n}{\sigma}\right]+\left[(1-\beta)\left\{\frac{(\theta-\rho)}{\sigma}+n\left(\frac{1}{\sigma}-1\right)\right\}\right]+(1-\beta) n
\end{gathered}
$$

Similar to Lucas' model, we observe that if the risk aversion coefficient, $\sigma$, is high then the agents' consumption growth rate is lower - negatively impacting the economy's growth rate. On the other hand, if the intertemporal discount rate is small, the economy will grow faster. It occurs since if agents are valuing future consumption more, the greater the savings will be. In addition, the greater the amount $\boldsymbol{\theta}$ of human capital employed in producing more human capital, the faster the economy will grow. Finally, moving from the sphere of similarities and moving towards the effects of institutions on growth (equation 2), according to equation 14, we observe that the higher the rate of growth of institutions over time, $n$, the higher will be the rate of output growth. 


\section{Empirical Model and Database}

Equation 2 attests that a country's level of activity, $Y$, is a function of its physical capital $(k)$, human capital $(H)$ and its institutions (I). Thus, by linearizing 2 and inserting an idiosyncratic error term, $\varepsilon$, we obtain the empirical model to be tested:

$$
Y_{i, t}=\beta_{0}+\beta_{1} K_{i, t}+\beta_{2} H_{i, t 1}+\beta_{3} I_{i, t}+\varepsilon_{i, t}
$$

The proposition behind Lucas' (1988) hypothesis is that the higher the level of physical and human capital, the more efficient the production process becomes - reflecting an increase in the product/worker ratio. Equally, institutions are expected to positively influence the level of activity as, according to Acemoglu et al. (2005), better political and economic institutions broaden the effect of human capital on the level of activity.

For the estimation of equation 15, we used a set of variables that cover 40 countries in a sequence of three-time cuts, in the years 2000, 2005 and 2010. The variables seek to capture the activity level, physical capital, institutions and human capital of the countries.

As a proxy for activity level, we use World Bank data for GDP per capita - Log (per capita GDP) (Note 9), defined as gross domestic product divided by the middle-aged population. The World Bank Gross Fixed Capital Formation $\log (G F C F)$ - variable includes land improvements; purchase of plants, machinery and equipment; and the construction of roads, railways and the like, including schools, offices, hospitals, private residences, and commercial and industrial buildings.

We built a human capital index via the Multivariate Factor Analysis technique (Note 10). Based on Becker (1994), Barro (2001), Cervellati and Sunde (2005) and Atun et al (2007) (Note 11) we submit the variables - also collected from the World Bank - of education, "Average years of study of the population aged between 25 years and 64 years old "; health, "Life expectancy at birth (years)"; high-tech production, "Export of information and communication technology services"; and inventive production, "Patent Applications by Residents in National Offices" to the Factor Analysis, for each sample year (2000, 2005 and 2010).

We use the Index of Economic Freedom overall score, produced by the Heritage Foundation, as a proxy for the Economic and Political Institutions. The scores ranging from 0 to 100 focus on four key aspects of a country's economic environment that are usually influenced by government action: Rule of Law, Government Size, Regulatory Efficiency and Market Openness. To evaluate such aspects, the index measures 12 components which can jointly capture a countries' economic and political institutions quality. These components are Property Law, Judicial Effectiveness, Government Integrity, Tax Burden, Government Expenditure, Tax Health, Business Freedom, Work Freedom, Monetary Freedom, Business Freedom, Investment Freedom and Financial Freedom.

Therefore, it is possible to assume a direct relationship between the scores and the institutions of the countries, where a higher score reports a higher institutional level as well.

\section{Results}

In the Factor Analysis application, we selected only one factor in each cross-section year, which represents $78 \%, 94 \%$ and $100 \%$ (Note 12) of the sample variation, respectively (Note 13). Appendix 2 displays all the analyzed countries ranked in ascending order according to the FA scores. Overall, we note that the countries with the highest scores the highest ranking in the human capital index - are those with the highest level of economic growth.

With the results of the Factor Analysis in hand, we estimate the extended model, 15, and the original Lucas model via panel data (Note 14). The first column of Table 1 displays the results of equation 15 - estimated by POLS (Note 15). Regarding the model quality of adjustment, $\mathrm{R}^{2}$, it indicates that $78 \%$ of per capita GDP variation is explained by independent variables. The coefficient measuring the effect of physical capital - Log $(G F C F)$ - is positive and significant at $99 \%$ confidence, reporting that a $1 \%$ increase in physical capital leads to a $0.13 \%$ raise of the economic activity. Following Lucas (1988), we can comprehend that the greater the stock of available physical capital, the greater will be the labour productivity - reflecting positively on the product. The variable that measures the role of human capital over the output - Log $(\mathrm{HCI})$ - is also positive and significant at $99 \%$ confidence, reporting a $1 \%$ improvement in knowledge stock generating - on average - a 1.1\% increase in the economic output. Such output occurs since according to Lucas (1988), as workers have more knowledge, more productive they become, resulting in a greater level of production. 
Table 1. Panel regression for economic growth

\begin{tabular}{|c|c|c|c|c|}
\hline & POLS & & IV & \\
\hline Model/variables & $\begin{array}{l}\text { Extended } \\
\text { model }\end{array}$ & Lucas (1988) & Extended model & Lucas (1988) \\
\hline \multirow[t]{2}{*}{$\log (\mathrm{GFCF})$} & $0.13 * * *$ & $0.13 * * *$ & $0.10 * *$ & $0.09 *$ \\
\hline & $(0.002)$ & $(0.011)$ & $(0.025)$ & $(0.086)$ \\
\hline \multirow[t]{2}{*}{$\log (\mathrm{HCI})$} & $1.10 * * *$ & $1.53 * * *$ & $1.66 * * *$ & $1.92 * * *$ \\
\hline & $(0.000)$ & $(0.000)$ & $(0.000)$ & $(0.000)$ \\
\hline \multirow[t]{2}{*}{$\log (\mathrm{I})$} & $3.061 * * *$ & - & $1.53 *$ & - \\
\hline & $(0.000)$ & - & $(0.076)$ & - \\
\hline \multirow[t]{2}{*}{ Constant } & $-6.99 * * *$ & $5.59 * * *$ & -0.05 & $6.31 * * *$ \\
\hline & $(0.001)$ & $(0.000)$ & $(0.988)$ & $(0.000)$ \\
\hline Observations & 117 & 117 & 118 & 118 \\
\hline $\mathrm{R}^{2}$ & 0.78 & 0.71 & 0.78 & 0.71 \\
\hline
\end{tabular}

Note: The dependent variable is Log (per capita GDP).

$* * * \mathrm{p}<0.01, * * \mathrm{p}<0.05, * \mathrm{p}<0.1$

Standard errors in parentheses

However, these results are already consolidated in the literature thanks to Lucas' seminal work. Therefore, the contribution of the present work emerges when we propose to insert institutions as determinants for the product through human capital. In the first column, the coefficient that measures the effect of institutions on the output - Log (I) - is positive and significant at $99 \%$. Therefore, a $1 \%$ improvement in institutions produces a positive effect of $3.06 \%$ in GDP. This result corroborates the assumptions made by the theoretical model (equation 14), indicating that the level of economic activity and institutions are positively related.

In the second column, we estimate Lucas' model (1988) by POLS, evaluating the effect of physical capital and human capital on economic growth. The purpose of this exercise relies on comparing the estimation of the Lucas model with that obtained by the extended model - equation 2 . In other words, we verify how the significance and magnitude of the parameters of the Lucas' equation, 1, behave after being inserted the variable of institutions. $\mathrm{R}^{2}$ indicates that $71 \%$ of per capita GDP variation is explained by the behaviour of the exogenous variables. In addition, the coefficients obtained are positive and significant at $99 \%$. Thus, a positive $1 \%$ change in physical and human capital raises the output level by $0.13 \%$ and $1.53 \%$, respectively (Note 16 ).

Comparing the first and second column, we can highlight two main findings. The first refers to the difference between the degree of adjustment of the two models. As we insert institutions into Lucas' model, the per capita GDP explanatory power, $\mathrm{R}^{2}$, rises by 7 percentage points. The second relates to the magnitude of the estimated parameters, since as political and economic institutions are recognized as determinants for the activity level - i.e. they are inserted in the Lucas model -, the magnitude of the physical capital parameter remains constant. However, the effect of human capital on per capita GDP is considerably reduced, dropping from 1.53 to 1.1 points.

Although empirical evidence indicates a good fit of the extended model to express the relationship between the level of activity and the explanatory variables - physical capital, human capital and institutions - we recognize that it is possible that the results obtained by POLS do not reflect the precise relationship established between the explanatory and the dependent variables. According to Acemoglu et al (2014), a potential issue in OLS estimates when dealing with the relationship between human capital and economic growth comes from the inconsistency generated by reverse causality. For the authors, although there is a consensus in the literature indicating the effect of human capital towards economic growth, we cannot rule out an effect in the opposite direction; that is, higher income levels can, through various channels, lead to higher levels of education. 
To correct the estimation bias, Acemoglu et al (2014) suggest the use of the instrumental variables (IV) method (Note 17). To this end, the authors use the primary school enrollment rate of the late nineteenth century, specifically, the year 1870, to instrumentalize the human capital proxy of the years of study in 2005. Thus, in order to make the predicted ratios of POLS estimates robust, we repeat the exercises in columns 1 and 2 using IV. Based on Acemoglu et al (2014), we used as instrument for the human capital proxy - Log (HCI) - in 2000, 2005 and 2010, the primary school enrollment rate of the population aged 15-64 at the end of the XIX century, in the years 1890, 1900 and 1910, respectively (Note 18).

The third and fourth columns of Table 1 present the results of the extended model estimation via IV, equation 2, and the Lucas model, respectively. Similarly to the POLS analysis, the coefficients of the explanatory variables are significant and positive in both models, demonstrating that positive variations in physical capital, human capital and institutions positively affect the level of activity. Moreover, in terms of model adjustment and coefficient magnitude, the results reinforce the evidence from the POLS analysis, indicating that once we insert the institutional factor in the Lucas model, the explanatory power goes up by approximately 19 points - from 0.51 to 0.70 - and the coefficient measuring the effect of human capital on per capita GDP falls from 1.92 to 1.66 .

\section{Final Considerations}

In the present study, we investigated the role that political and economic institutions play in promoting the human capital factor in the Lucas model (1988). To this end, we developed a new theoretical model in which institutions are internalized as boosters for human capital stock. We then built a human capital index and implemented a Pooled Ordinary Least Squares (POLS) analysis - along with instrumental variables (IV) - for 40 countries in 2000, 2005 and 2010. This strategy therefore allowed us to test empirically how the variables of the Lucas model behave - as well as the level of growth - when the human capital variable is under the influence of institutions.

As predicted by the institutionalist authors, we observed that the level of a country's political and economic institutions indeed plays a fundamental role in economic growth through human capital. The comparative analysis between the Lucas model (1988) and the extended model proposed by our study demonstrates that Lucas model overestimates the contribution of human capital to growth since Lucas does not model the human capital variable according to the performance of institutions. We also noted the correlation between the institutional variable and the human capital. The effect of physical capital on growth remains statistically unchanged when comparing the extended (with institutions) model to Lucas's original model. In general, the evidence we presented corroborate Acemoglu et al (2014). According to the authors, empirical models that do not adequately control the effect of institutions over the level of activity tend to suffer from a serious omitted variable bias, with the effect of human capital on countries' output being overestimated - as institutions and human capital are correlated factors. Therefore, we can conclude that human capital serves as a channel of influence, through which institutions contribute to the growth process of countries.

This paper proves that the discussion regarding the impact of the institutional composition on the level of economic prosperity continues to be reinforced through the empirical findings. Based on the analysis proposed by Acemoglu et al (2012), it is possible to point to a strong and independent judiciary as being a central effort in the search for good institutions - i.e. which act according to what the de jure power establishes, oriented to the general benefit and not under the influence of individuals or small groups. The relationship between institutions and the distribution of resources in society, in turn, reinforces the constant need for policing over institutions and also suggests a better level of income distribution as an important mechanism for promoting more inclusive institutions.

This study we developed is another effort in the area of institutional economics. We aim to bring additional results to the great institutional discussion already established by proposing an extension to the Lucas model (1988). We highly encourage authors to further refining the effect of institutions over other variables - as they become available for measuring human capital. We also suggest to new researchers focusing on working with countries with great institutional diversity, deepening even further in the specificities and patterns that may be identified in the many institutional compositions of our economies.

\section{References}

Acemoglu, D., \& Robinson, J. A. (2012). Why the nations fail: the origins of power, prosperity, and poverty. Crown Business, New York.

Acemoglu, D., Gallego, F. A., \& Robinson, J. A. (2014). Institutions, human capital, and development. Annual Review of Economics, 6, 875-912. https://doi.org/10.1146/annurev-economics-080213-041119 
Acemoglu, D., Johnson, S., \& Robinson, J. A. (2005). Institutions as a fundamental cause of long-run growth. Handbook of Economic Growth, 1, 385-472. https://doi.org/10.3386/w10481

Almeida, E. S. (2012). Applied spatial econometrics. Campinas: Alínea Editora, 1, 498.

Atun, R. A., Harvey, I., \& Wild, J. (2007). Innovation, patents and economic growth. International Journal of Innovation Management, 11(2), 279-297. https://doi.org/10.1142/S1363919607001758

Barcelos, G. L., \& Salles, A. O. T. (2011). The Post-General Theory debate between Keynes and Harrod and the emergence of dynamic analysis in economic science, paper presented at the National Meeting of Economy-ANPEC, no. 39.

Barro, R. J. (2001). Human capital and growth. American Economic Review, 91(2), 12-17. https://doi.org/10.1257/aer.91.2.12

Becker, G. S. (1994). Human capital revisited. In Human Capital: A Theoretical and Empirical Analysis with Special Reference to Education (pp.15-28). The University of Chicago Press.

Cervellati, M., \& Sunde, U. (2005). Human capital formation, life expectancy, and the process of development. American Economic Review, 95(5), 1653-1672. https://doi.org/10.1257/000282805775014380

Dias, J., \& Tebaldi, E. (2012). Institutions, human capital, and growth: The institutional mechanism. Structural Change and Economic Dynamics, 23(3), 300-312.

Hair, J. F., Black, W. C., Babin, B. J., Anderson, R. E., \& Tatham, R. L. (2005). Multivariate data analysis (5th ed). Porto Alegre: Bookman.

Harrod, R. F. (1939). An Essay in Dynamic Theory. The Economic Journal, 49(193), 14-33. https://doi.org/10.1111/ecoj.12224

Lee, J. W., \& Lee, H. (2016). Human Capital in the Long Run. Journal of Development Economics, 122, $147-169$. https://doi.org/10.1016/j.jdeveco.2016.05.006

Lucas, R. E. (1988). On the mechanics of economic development. Journal of Monetary Economics, 22(1), 3-42. https://doi.org/10.1016/0304-3932(88)90168-7

North, D. C. (1981). Structure and change in economic history. W. W. Norton \& Company.

North, D. C. (1990). Institutions, Institutional Change and Economic Performance. Cambridge University Press.

North, D. C., \& Robert, T. (1973). The Rise of the Western World: A New Economic History. Cambridge University Press.

Romer, P. M. (1986). Increasing returns and long-run growth. Journal of Political Economy, 94, $1002-1037$. https://doi.org/10.1086/261420

Solow, R. M. (1956). A contribution to the theory of economic growth. The Quarterly Journal of Economics, 70(1), 65-94. https://doi.org/10.2307/1884513

Tebaldi, E., \& Elmslie, B. (2008). Institutions, innovation and economic growth. Journal of Economic Development, $33(2), 1-27$.

\section{Notes}

Note 1. According to Dias and Tebaldi (2012 p. 301): 'Lucas (1988) states that economic development is related to the process of knowledge accumulation, which produces an institution or social capital, represented by the average knowledge in society.'

Note 2. As in the discussion started by North and Thomas (1973).

Note 3. The authors cite the Black Death of the 19th century as one of these critical events in history.

Note 4. Pre-existing institutions are defined by various factors such as cultural and historical elements, social relations, and random events.

Note 5. Political centralization is necessary for the establishment of law and order, thereby ensuring the fundamental guarantees that a nation must possess in order to offer incentives that leads to economic prosperity.

Note 6. The central cause for such an argument is that the absence of creative destruction - not fueled by the fears that power holders have to undermine the status quo in which society is already organized - a factor that is 
responsible for technological advancement in economies, eventually ends making any level of sustainable growth impossible.

Note 7. That is, as Solow (1956) demonstrates the role of technology in making work more efficient in the production function.

Note 8 . We observe these positive effects by encouraging greater interaction between workers - via improvements in social capital, for example - as institutions, therefore, produce a greater externality of knowledge in the production process.

Note 9. GDP is in 2010 constant prices.

Note 10. The main idea of the Factor Analysis is to identify which socioeconomic variables are the most relevant to explain the variation of the data, in order to reduce them to a new group of variables, the factors. Each factor will contain the name of the variable set that has the highest correlation with it. For more details on the Factor Analysis technique, see Hair (2005).

Note 11. The authors discuss and/or test how these variables are related to human capital and contribute to economic growth.

Note 12. According to Hair (2005), in social sciences, where information is generally less accurate, it is plausible to consider a solution that explains $60 \%$ of the total (in some cases even less) variance as satisfactory. Thus, we use the cumulative $75 \%$ explanation of the original variables, which covers only the first factor in each year.

Note 13. Appendix 1 shows the results of the Factor Analysis, with factor composition and Kaiser-Meyer-Olkin (KMO) statistics for PA each year. KMO statistics are used to test the consistency of PA application, being its values placed between 0 and 1 . Values of 0.80 or more are considered admirable; between 0.70 and 0.80 , medium; between 0.60 and 0.70 , mediocre; between 0.50 and 0.6 , bad; and below 0.50 , unacceptable. For the three years, it is found that the variables with the highest explanatory power for the data set variation are education and life expectancy, in addition, KMO statistics were above 0.60 .

Note 14. According to Almeida (2012), estimates using longitudinal data are a way to accommodate the spatial heterogeneity that manifests in the parameters and error term of a regression. In addition, working with panel data generally yields gains in asymptotic estimator properties, controlling for unobserved effects, and reducing data collinearity. To obtain the results in terms of percentage variations, we resort to the logarithmization of the variables. Due to the logarithmization process, we call for a transformation of the Factor Analysis scores to generate nonnegative values. The transformation sought to maintain the order and magnitude difference of the original scores. Thus, for each year, we selected the lowest score, [score]_min, and obtained the difference in the scores of $\mathrm{n}$ observations concerning this one. In formal terms, the new value for observation, [score]_n $\mathrm{n}^{\wedge *}$, is given by: [score]_n $\mathrm{n}^{\wedge *}=[$ score $] \mathrm{n}-[\mathrm{score}] \_\min , \operatorname{com} n=1,2,4, \ldots 40$.

Note 15. POLS estimation consists of stacking the observations in a single cross-section and then estimating the parameters by Ordinary Least Squares (OLS). For more details, see Wooldridge (2002).

Note 16. In order to verify the presence of endogeneity in the estimated models, we made a regression of the residues against the explanatory variables (Appendix 3). The results suggest the non-significance of the parameters, indicating the consistency of the estimates.

Note 17. The IV method predicts a two-stage estimation of the relationship between the dependent variable and the explanatory variables. In the first stage, the relationship between the endogenous explanatory variable and the other exogenous explanatory variables is estimated and the instrument - variable with a high correlation with the endogenous explanatory variable and no correlation with the error term. In the second stage, the relationship between the dependent variable and the other exogenous explanatory variables and the predicted values of the endogenous explanatory variable is estimated. For more details, see Wooldridge (2002).

Note 18. The variable Primary School Enrollment rate for the population aged 15-64 was extracted from Lee and Lee (2016). Moreover, in the estimation of the first stage, the logarithm of the primary school enrollment rate lnprm was used. 


\section{Appendix A}

Variables Correlation With KMO Factors and Statistics

\begin{tabular}{lllllll}
\hline Year & 2000 & & 2005 & & 2010 \\
\hline Variables \Factor & Factor 1 & Factor 2 & Factor 1 & Factor 2 & Factor 1 & Factor 2 \\
\hline educ & 0.6649 & 0.2581 & 0.6272 & 0.2577 & 0.6604 & 0.2163 \\
\hline lexp & 0.6668 & 0.2322 & 0.6065 & 0.1825 & 0.6196 & 0.1221 \\
\hline pa & 0.2580 & 0.5406 & 0.2983 & 0.4213 & 0.2245 & 0.3728 \\
\hline ict & 0.3473 & 0.5484 & 0.3461 & 0.4251 & 0.3592 & 0.4048 \\
\hline KMO & 0.6730 & & 0.6730 & & 0.6262 &
\end{tabular}

Source: Prepared from estimates.

Note: The dependent variables are "average number of years of total schooling across all education levels" (educ), "life expectancy at birth" (lexp), "patent applications by residents in national offices" (pa) and "information and communication technology service exports" (ict).

\section{Appendix B}

Factor Analysis Scores for the Years 2000, 2005 and 2010

\begin{tabular}{|c|c|c|c|c|c|}
\hline 2000 & & 2005 & & 2010 & \\
\hline Country & Score & Country & Score & Country & Score \\
\hline South Africa & -1.588526 & South Africa & -1.645458 & South Africa & -1.523305 \\
\hline India & -1.537812 & Bangladesh & -1.271994 & Bangladesh & -1.296017 \\
\hline Bangladesh & -1.45834 & India & -1.243655 & Morocco & -1.222189 \\
\hline Morocco & -1.317865 & Morocco & -1.199067 & India & -1.20314 \\
\hline Egypt & -0.9284954 & Egypt & $\begin{array}{l}- \\
0.9198097\end{array}$ & Egypt & -1.035694 \\
\hline Thailand & -0.8107104 & Philippines & $\begin{array}{l}- \\
0.7742772\end{array}$ & Philippines & -0.8919634 \\
\hline Philippines & -0.7545543 & Thailand & $\begin{array}{l}- \\
0.6414008\end{array}$ & Tunisia & -0.6285537 \\
\hline Brazil & -0.7312374 & Colombia & $\begin{array}{l}- \\
0.6362991\end{array}$ & Brazil & -0.6089301 \\
\hline Colombia & -0.6093456 & Brazil & $\begin{array}{l}- \\
0.6025319\end{array}$ & United States & -0.6084934 \\
\hline Tunisia & -0.5872911 & Tunisia & $\begin{array}{l}- \\
0.5798982\end{array}$ & Thailand & -0.5697126 \\
\hline United States & -0.4129152 & United States & $\begin{array}{l}- \\
0.4984709\end{array}$ & Colombia & -0.4553139 \\
\hline China & -0.384685 & China & $\overline{-}-2936164$ & Peru & -0.4467457 \\
\hline Peru & -0.3084984 & Russia & $\begin{array}{l}- \\
0.2746321\end{array}$ & China & -0.4272388 \\
\hline Russia & -0.2480756 & Uruguay & $\begin{array}{l}- \\
0.2534959\end{array}$ & Uruguay & -0.3842694 \\
\hline Mexico & -0.2000707 & Peru & $\overline{0}-2193198$ & Mexico & -0.3034097 \\
\hline Bulgaria & -0.1147114 & Mexico & $\begin{array}{l}- \\
0.2089145\end{array}$ & Argentina & -0.2151873 \\
\hline Uruguay & -0.1027735 & Portugal & $\begin{array}{l}- \\
0.1665274\end{array}$ & Portugal & -0.186023 \\
\hline
\end{tabular}




\begin{tabular}{llllll}
\hline Jamaica & -0.074666 & Jamaica & - & Russia & -0.1595116 \\
& & & 0.1216701 & & -0.1551836 \\
\hline Argentina & -0.0483719 & Argentina & - & Jamaica & \\
& & & 0.1200658 & & -0.0963784 \\
\hline Romania & 0.0218742 & Romania & - & Bulgaria & \\
& & & 0.1116163 & & -0.0884699 \\
\hline Portugal & 0.0251189 & Bulgaria & - & Romania & \\
\hline Hungary & 0.1940508 & Chile & 0.1344535 & Chile & 0.0975344 \\
\hline Chile & 0.2369838 & Hungary & 0.1554265 & Hungary & 0.1492833 \\
\hline Poland & 0.241313 & Poland & 0.2142966 & Poland & 0.2375489 \\
\hline Greece & 0.4084024 & Luxembourg & 0.3695384 & New Zealand & 0.4038302 \\
\hline Luxembourg & 0.4154634 & Greece & 0.4035965 & Greece & 0.4341967 \\
\hline United Kingdom & 0.5539948 & Czech Republic & 0.5259696 & Luxembourg & 0.4717661 \\
\hline South Korea & 0.612106 & Switzerland & 0.5577995 & Czech Republic & 0.5339431 \\
\hline Switzerland & 0.6167299 & Netherlands & 0.5872815 & Norway & 0.5762146 \\
\hline Germany & 0.6256459 & New Zealand & 0.6223932 & Australia & 0.6083979 \\
\hline France & 0.6785437 & Norway & 0.6465203 & Netherlands & 0.6643482 \\
\hline Czech Republic & 0.6935099 & Australia & 0.6520376 & Sweden & 0.7021803 \\
\hline Netherlands & 0.6992378 & Sweden & 0.7050226 & France & 0.7534097 \\
\hline Norway & 0.7722704 & France & 0.7054504 & South Korea & 0.8371592 \\
\hline Australia & 0.7779676 & South Korea & 0.710041 & Canada & 0.8716802 \\
\hline Canada & 0.8236649 & United Kingdom & 0.8367925 & Switzerland & 0.9344751 \\
\hline New Zealand & 0.82897 & Germany & 0.8401804 & Germany & 0.9529409 \\
\hline Sweden & 0.8888561 & Canada & 0.8439423 & United Kingdom & 0.9742275 \\
\hline Japan & 1.030486 & United States & 1.170183 & Japan & 1.068849 \\
\hline United States & 1.073756 & Japan & 1.18596 & United States & 1.233742 \\
\hline Source Preared from & est9an & & & & \\
\hline
\end{tabular}

Source: Prepared from estimates.

\section{Appendix C}

Residual Endogeneity Test

\begin{tabular}{|c|c|c|}
\hline Variables $\backslash$ Model & Column 1 & Column 2 \\
\hline Log (Gross fixed capital formation) & 0.000 & 0.000 \\
\hline Log (Human Capital Index) & 0.000 & 0.000 \\
\hline Log (Overall score - Institutions) & 0.000 & - \\
\hline Constant & 0.000 & 0.000 \\
\hline Observations & 117 & 117 \\
\hline $\mathrm{R}^{2}$ & 0.000 & 0.000 \\
\hline
\end{tabular}

Source: Prepared from estimates.

$* * * \mathrm{p}<0.01, * * \mathrm{p}<0.05, * \mathrm{p}<0.1$

Standard errors in parentheses 


\section{Appendix D}

\section{The Extended Model}

$$
\begin{gathered}
y=A k_{t}^{\beta}\left(u_{t} h_{t} I_{t}\right)^{1-\beta} \\
I_{t}=J e^{n t+\sum_{\tau=1}^{t} \varepsilon_{\tau}} \text { given that } \sum_{\tau=1}^{t} \varepsilon_{\tau}=0, \text { it has been } I_{t}=J e^{n t} \\
y=A k_{t}^{\beta}\left(u_{t} h_{t} J e^{n t}\right)^{1-\beta} \\
\dot{h}=\theta h\left(1-u_{t}\right) \\
\dot{k}=A k_{t}^{\beta}\left(u_{t} h_{t} I_{t}\right)^{1-\beta}-C \\
U(C t)=\int_{0}^{\infty} e^{-\rho t} \frac{c_{t}^{1-\sigma}}{1-\sigma}
\end{gathered}
$$

applying the Hamiltonian function

$$
L=\int_{1}^{\infty} e^{-\rho t} \frac{c_{t}^{1-\sigma}}{1-\sigma}+V\left\{A k_{t}^{\beta}\left(u_{t} h_{t} J e^{n t}\right)^{1-\beta}-C\right\}+\lambda\left\{\theta h\left(1-u_{t}\right)\right\}
$$

FOC

$$
\begin{gathered}
\frac{\partial L}{\partial u}=V\left\{A k_{t}^{\beta}(1-\beta)\left(h_{t} J e^{n t}\right)^{1-\beta} u_{t}^{-\beta}\right\}-\lambda \theta h=0 \\
\frac{\partial L}{\partial c}=e^{-\rho t} c_{t}^{-\sigma}-V=0 \\
\frac{\partial L}{\partial k}=V\left\{\beta A k_{t}^{\beta-1}\left(u_{t} h_{t} J e^{n t}\right)^{1-\beta}\right\} \\
\frac{\partial L}{\partial h}=V\left\{(1-\beta) A k_{t}^{\beta}\left(u_{t} J e^{n t}\right)^{1-\beta} h_{t}^{-\beta}\right\}+\lambda\left\{\theta\left(1-u_{t}\right)\right\}
\end{gathered}
$$

transversality condition

$$
\begin{gathered}
\frac{\partial L}{\partial k}=-\dot{V} \\
\frac{\partial L}{\partial h}=-\dot{\lambda} \\
\frac{\partial L}{\partial u}=0
\end{gathered}
$$

(8) equals to (10)

$$
\begin{aligned}
& V\left\{\beta A k_{t}^{\beta-1}\left(u_{t} h_{t} J e^{n t}\right)^{1-\beta}\right\}=-\dot{V} \\
& \frac{\dot{V}}{V}=-\left\{\beta A k_{t}^{\beta-1}\left(u_{t} h_{t} J e^{H_{0} n t}\right)^{1-\beta}\right\}
\end{aligned}
$$

(9) equals to (11)

$$
V\left\{(1-\beta) A k_{t}^{\beta}\left(u_{t} J e^{n t}\right)^{1-\beta} h_{t}^{-\beta}\right\}+\lambda\left\{\theta\left(1-u_{t}\right)\right\}=-\dot{\lambda}
$$

(12) equals to (6) 


$$
\left\{A k_{t}^{\beta}(1-\beta)\left(h_{t} J e^{n t}\right)^{1-\beta} u_{t}^{-\beta}\right\}-\lambda \theta h=-\dot{\lambda}
$$

log-linearizing (7)

$$
-\rho t \ln e-\sigma \ln c t-\ln V=0
$$

Deriving from $\mathrm{t}$

$$
\begin{gathered}
-\rho-\sigma \frac{\dot{c}}{c}-\frac{\dot{V}}{V}=0 \\
\frac{\dot{c}}{c}=\frac{-\frac{\dot{V}}{V}-\rho}{\sigma}
\end{gathered}
$$

Substituting (13) into (16),

$$
\frac{\dot{c}}{c}=\frac{\beta A k_{t}^{\beta-1} u_{t}^{1-\beta} h_{t}^{1-\beta} J^{1-\beta} e^{n t(1-\beta)}-\rho}{\sigma}=\gamma
$$

Dividing (4) by $k_{t}$

$$
\frac{\dot{k}}{k}=A k_{t}^{-(1-\beta)} u_{t}^{1-\beta} h_{t}^{1-\beta} J^{1-\beta} e^{n t(1-\beta)}-\frac{c_{t}}{k_{t}}
$$

In 17 , if we multiply $\gamma$ by $\sigma$, adding $\rho$ and divide everything by $\beta$, we have M:

$$
M=\frac{\gamma \sigma+\rho}{\beta}
$$

Performing the procedure both sides of (17)

$$
M=\frac{\gamma \sigma+\rho}{\beta}=\frac{\frac{\beta A k_{t}^{\beta-1} u_{t}^{1-\beta} h_{t}^{1-\beta} J^{1-\beta} e^{n t(1-\beta)} \sigma-\rho \sigma}{\sigma}+\rho}{\beta}
$$

simplifying

$$
M=\frac{\gamma \sigma+\rho}{\beta}=A k_{t}^{\beta-1} u_{t}^{1-\beta} h_{t}^{1-\beta} J^{1-\beta} e^{n t(1-\beta)}
$$

Note that equation (19) is equal to the first term on the right-hand side of equation (18)

Substituting (19) into (18)

$$
\frac{\dot{k}}{k}=\frac{\gamma \sigma+\rho}{\beta}-\frac{C_{t}}{k_{t}}=\gamma_{k}
$$

log-linearizing (20)

$$
\ln \gamma+\ln \sigma-\ln \beta+\ln \rho-\ln \beta-\ln c_{t}+\ln k_{t}=\ln \gamma_{k}
$$

Deriving from $\mathrm{t}$, we have:

$$
\frac{\dot{k}}{k}=\frac{\dot{c}}{c}=\gamma=\gamma_{k}
$$

From (3), we have to

$$
\frac{\dot{h}}{h}=\theta(1-u)=\gamma_{h}
$$

From (19) 


$$
\begin{gathered}
\frac{\gamma \sigma+\rho}{\beta}=A k_{t}^{\beta-1} u_{t}^{1-\beta} h_{t}^{1-\beta} J^{1-\beta} e^{n t(1-\beta)} \\
\frac{\gamma \sigma+\rho}{A \beta}=k_{t}^{\beta-1} u_{t}^{1-\beta} h_{t}^{1-\beta} J^{1-\beta} e^{n t(1-\beta)}
\end{gathered}
$$

log-linearizing (23)

$$
\begin{gathered}
\ln \gamma+\ln \sigma-\ln A-\ln B+\ln \rho-\ln A-\ln B \\
=(\beta-1) \ln k_{t}+(1-\beta) \ln u_{t}+(1-\beta) \ln h_{t}+(1-\beta) \ln J+n t(1-\beta)
\end{gathered}
$$

Deriving from $\mathrm{t}$

$$
0=-(1-\beta) \frac{\dot{k}}{k}+(1-\beta) \frac{\dot{h}}{h}+n(1-\beta)
$$

Isolating (24) to $\frac{\dot{h}}{h}$

$$
\frac{\dot{h}}{h}=\frac{(1-\beta)}{(1-\beta)} \frac{\dot{k}}{k}-\frac{(1-\beta) n}{(1-\beta)}=\frac{(1-\beta)}{(1-\beta)} \gamma-\frac{(1-\beta) n}{(1-\beta)}=\gamma_{h}=\gamma-n
$$

Dividing (6) by $\lambda$

$$
\frac{V}{\lambda}\left\{A k_{t}^{\beta}(1-\beta)\left(h_{t} J e^{n t}\right)^{1-\beta} u_{t}^{-\beta}\right\}-\theta h=0
$$

Isolating to $\frac{V}{\lambda}$,

$$
\begin{aligned}
& \frac{V}{\lambda}=\frac{\theta h}{A k_{t}^{\beta}(1-\beta)\left(h_{t} J e^{n t}\right)^{1-\beta} u_{t}^{-\beta}} \\
& \frac{V}{\lambda}=\frac{\theta}{A k_{t}^{\beta}(1-\beta) u_{t}^{-\beta} h_{t}^{-\beta} J^{1-\beta} e^{n t(1-\beta)}}
\end{aligned}
$$

log-linearizing (26)

$$
\ln V-\ln \lambda=\ln \theta-\ln A-\beta \ln k_{t}-\ln (1-\beta)+\beta \ln u_{t}+(\beta) \ln h_{t}-n t(1-\beta)-(1-\beta) \ln J
$$

Deriving from $\mathrm{t}$

$$
\frac{\dot{V}}{V}-\frac{\dot{\lambda}}{\lambda}=-\frac{\dot{\beta} k}{k}+(\beta) \frac{\dot{h}}{h}-n(1-\beta)
$$

\{Note: this result was obtained due to the fact that $\frac{\dot{u}}{u}=0$, which will be proved in equation (34)\} Isolating to $\frac{\dot{\lambda}}{\lambda}$

$$
\frac{\dot{\lambda}}{\lambda}=\frac{\dot{V}}{V}+\frac{\dot{\beta} k}{k}-(\beta) \frac{\dot{h}}{h}+n(1-\beta)=\frac{\dot{V}}{V}+\beta \gamma-(\beta) \gamma_{h}+n(1-\beta)
$$

From (13), we can see that

$$
\frac{\dot{V}}{V}=-(\gamma \sigma+\rho)
$$

*Proof of (27'): from (17) we have

$$
\frac{\beta A k_{t}^{\beta-1} u_{t}^{1-\beta} h_{t}^{1-\beta} J^{1-\beta} e^{n t(1-\beta)}-\rho}{\sigma}=\gamma
$$

Multiplying $\gamma$ by $\sigma$, adding $\rho$ and multiplying all by -1 , we have 


$$
-\left[\frac{\beta A k_{t}^{\beta-1} u_{t}^{1-\beta} h_{t}^{1-\beta} J^{1-\beta} e^{n t(1-\beta)} \sigma-\sigma \rho}{\sigma}+\rho\right]=-(\gamma \sigma+\rho)
$$

Simplifying

$$
-\beta A k_{t}^{\beta-1} u_{t}^{1-\beta} h_{t}^{1-\beta} J^{1-\beta} e^{n t(1-\beta)}=-(\gamma \sigma+\rho)
$$

Note that the left side of the equation is exactly equal to equation (13), so

$$
-\beta A k_{t}^{\beta-1} u_{t}^{1-\beta} h_{t}^{1-\beta} J^{1-\beta} e^{n t(1-\beta)}=-(\gamma \sigma+\rho)=\frac{\dot{V}}{V}
$$

*end of the proof

To find $\frac{\dot{\lambda}}{\lambda}$, we can divide the two sides of (14) by $\lambda$

$$
\frac{V}{\lambda}\left\{(1-\beta) A k_{t}^{\beta}\left(u_{t} J e^{n t}\right)^{1-\beta} h_{t}^{-\beta}\right\}+\left\{\theta\left(1-u_{t}\right)\right\}=-\frac{\dot{\lambda}}{\lambda}
$$

Isolating to $\frac{\dot{\lambda}}{\lambda}$

$$
-\frac{V}{\lambda}\left\{(1-\beta) A k_{t}^{\beta}\left(u_{t} J e^{n t}\right)^{1-\beta} h_{t}^{-\beta}\right\}-\left\{\theta\left(1-u_{t}\right)\right\}=\frac{\dot{\lambda}}{\lambda}
$$

Replacing (26) into (29)

$$
\frac{\dot{\lambda}}{\lambda}=-\frac{\theta}{A k_{t}^{\beta}(1-\beta) u_{t}^{-\beta} h_{t}^{-\beta} J^{1-\beta} e^{n t(1-\beta)}}\left\{(1-\beta) A k_{t}^{\beta}\left(u_{t} J e^{n t}\right)^{1-\beta} h_{t}^{-\beta}\right\}-\left\{\theta\left(1-u_{t}\right)\right\}
$$

Simplifying

From (27), isolating for $\frac{\dot{V}}{V}$, it has been

$$
\frac{\dot{\lambda}}{\lambda}=-\theta u_{t}-\theta+\theta u_{t}=-\theta
$$

$$
\frac{\dot{V}}{V}=\frac{\dot{\lambda}}{\lambda}-\beta \gamma+(\beta) \gamma_{h}-n(1-\beta)
$$

Replacing (30)

$$
\frac{\dot{V}}{V}=-\theta-\beta \gamma+(\beta) \gamma_{h}-n(1-\beta)
$$

Replacing (25)

$$
\frac{\dot{V}}{V}=-\theta-\beta \gamma+(\beta)[\gamma-n]-n(1-\beta)
$$

Simplifying

$$
\frac{\dot{V}}{V}=-\theta-n
$$

Substituting (31) into (16):

$$
\frac{\dot{c}}{c}=\frac{\theta+H_{0} n-\rho}{\sigma}=\gamma=\frac{\theta-\rho}{\sigma}+\frac{n}{\sigma}
$$

From (21) and (32):

$$
\frac{\dot{k}}{k}=\gamma=\frac{\theta-\rho}{\sigma}+\frac{n}{\sigma}
$$

**Proving that $\frac{\dot{u}}{u}=0$, 
From 3, we have to

$$
\left(1-u_{t}\right)=\frac{\dot{h}}{h \theta}
$$

Replacing (25):

$$
\begin{aligned}
& \left(1-u_{t}\right)=\frac{\gamma}{\theta}-\frac{n}{\theta} \\
& u_{t}=1-\frac{\gamma}{\theta}+\frac{n}{\theta}
\end{aligned}
$$

log-linearizing both sides

$$
\ln u_{t}=\ln 1+\ln \theta-\ln \gamma+\ln n+\ln -\ln \theta
$$

Deriving from $\mathrm{t}$

$$
\frac{\dot{u}}{u}=0
$$

*end of the proof

From 25 and 32, we have

$$
\gamma_{h}=\frac{\theta+n-\rho}{\sigma}-n=\frac{\theta}{\sigma}+\frac{n}{\sigma}-\frac{\rho}{\sigma}-n=\frac{(\theta-\rho)}{\sigma}+n\left(\frac{1}{\sigma}-1\right)
$$

$\log$-linearizing 2 , and deriving in relation to time, we have:

$$
\begin{gathered}
\frac{\dot{y}}{y}=\beta \frac{\dot{k}}{k}+(1-\beta) \frac{\dot{h}}{h}+(1-\beta) n \\
\frac{\dot{y}}{y}=\beta\left[\frac{\theta-\rho}{\sigma}+\frac{n}{\sigma}\right]+\left[(1-\beta)\left\{\frac{(\theta-\rho)}{\sigma}+n\left(\frac{1}{\sigma}-1\right)\right\}\right]+(1-\beta) n
\end{gathered}
$$

